\title{
Qualitative and quantitative daylight optimisation by shading device experimentation
}

\author{
M. Fajkus \\ The University of Texas at Austin, USA
}

\begin{abstract}
Daylight has been an influential design factor since the beginning of architectural practice, though qualitative concerns, such as atmosphere and effect, have largely outweighed quantitative considerations such as functional and thermal optimisation. This imbalance has only widened as architectural and engineering disciplines have become increasingly specialised, such that architects are exclusively responsible for qualitative design aspects while engineers are responsible for quantitative issues. Thus, the purpose of this body of work was to initiate the design of a prototypical shading structure design which accounts for and encourages overlap between qualitative and quantitative factors throughout the design process. The prototype was developed and tested both by simulation software as well as in physical form as it was constructed and rigorously measured in a unique a full-scale Facade Lab to optimise daylight transmission performance relative to conventional shading systems. Results from the initial prototype test show that even by simply manipulating the singular variable of shading device geometry for an optimised balance of daylight and permissible views, improvements in both categories are immediately achieved relative to comparable conventional shading structures, while using less material. By increasing our quantitative understanding of the cause and effect relationship between shading device design and daylight transmission as well as thermal performance, qualitative design processes can be rigorously measured in an integrated manner. Thus, the research suggests that collaborative common ground can be achieved between architects and engineers from the beginning to the end of the design process, to optimise daylight levels and enhance both the visual experience as well as the thermal performance of architectural spaces.
\end{abstract}

Keywords: daylighting, interdisciplinary collaboration, shading device. 


\section{Introduction}

When sunlight passes through tree foliage, it creates irregularly scattered patches of light of various sizes on the ground. This dappled light has an elusive appeal and sitting under a shady tree offers delicate light modulation while providing a direct connection with to nature. The penetrating sunlight patterns, which create the appeal, can be rigorously charted as numerous variants of conical and elliptical rays, as done by Minnaert [1]. Most indoor environments, however, depend heavily on artificial light sources, while any natural light entering the space passes through punched windows in solid walls which can create glare, as the contrast of the unobstructed light is too harsh relative to darker portions of the room, as noted by Augustin [2]. We spend the vast majority of our time indoors, and the built environment that immediately surrounds us is influenced by many factors including scale, proportion, materiality, light, and colour. Historically, architectural research at universities and in the profession has focused primarily on these physical aspects, while issues related to the performance of buildings was conducted by architectural and structural engineers and only rarely connected to spatial explorations. As buildings continue to consume nearly $40 \%$ of all energy produced, according to USGBC [3], and as our natural resources are becoming increasingly scarce, the architectural profession has begun to recognise the need for more sustainable building practices.

The ever-pressing issue of energy efficiency must also be balanced with consideration of the human condition and the critical relationship between the human body and the external environment. As noted by Koster [4], the human body has evolved around the conditions of natural daylight. Our circadian rhythms are rooted in the natural cycle of light and dark. The best way forward for architectural design is to look back at our origins while testing and incorporating the latest technologies to optimize building envelope performance. The building envelope must strike an optimal balance between energy efficiency and spatial/formal perception. In terms of minimal internal energy use, the most "efficient" building might have no openings at all, although such an internal environment would be far from desirable due to a complete lack of natural light and views. Herzog [5] establishes that in order to maximise efficiency and perception of space, the transparent elements of a building are the most critical points for consideration, as these transparent surfaces are the primary conduit for thermal exchange as well as sunlight and daylight transmission. In addition to performing as the primary defining aesthetic feature of a building, Leslie [7] notes that the envelope provides an opportunity to enhance and expand upon our relationship with nature in terms of light, air, and views.

However, in most facade design processes, aesthetic issues have been the primary concern of architects, while energy-efficiency optimisation has been almost exclusively the role of architectural engineers. Simulation software has begun to bridge that gap as a collaborative tool, and now the Facade Lab at the University of Texas has been established as a physical full-scale facade testing tool to compliment its digital counterparts. Thus, the Facade Lab is meant to 
conduct a design process which is informed by two modes of qualitative measurements (virtual and physical) in addition to aesthetic considerations of the shading structure itself as well as view quality. This process is meant to encourage interdisciplinary collaboration between architects and engineers in the academy and the profession, to affect positive change in facade design energy optimization in addition to establishing parameters which can act as inspiration in formal and aesthetic decisions within tolerance margins.

\section{The Facade Lab: an innovative daylight testing tool}

Based on the need to facilitate experimental research related to the improvement of building envelope performance and to compliment virtual simulation data, the Facade Lab was established at The University of Texas in late 2009 to allow testing of innovative building components and systems, pairing the quantitative analysis of energy performance with the qualitative analysis of space, aesthetics, and design (see figure 1). The Facade Lab consists of a full-scale, single room space with a south-facing facade, which allows for thermal experiments as well as testing in the areas of day lighting, ventilation, and the use of direct and indirect solar energy. The small test box with exterior dimensions of approximately $4 \mathrm{~m} \times 5 \mathrm{~m} \times 3 \mathrm{~m}(\mathrm{w} / \mathrm{d} / \mathrm{h})$ is located on top of a campus building.

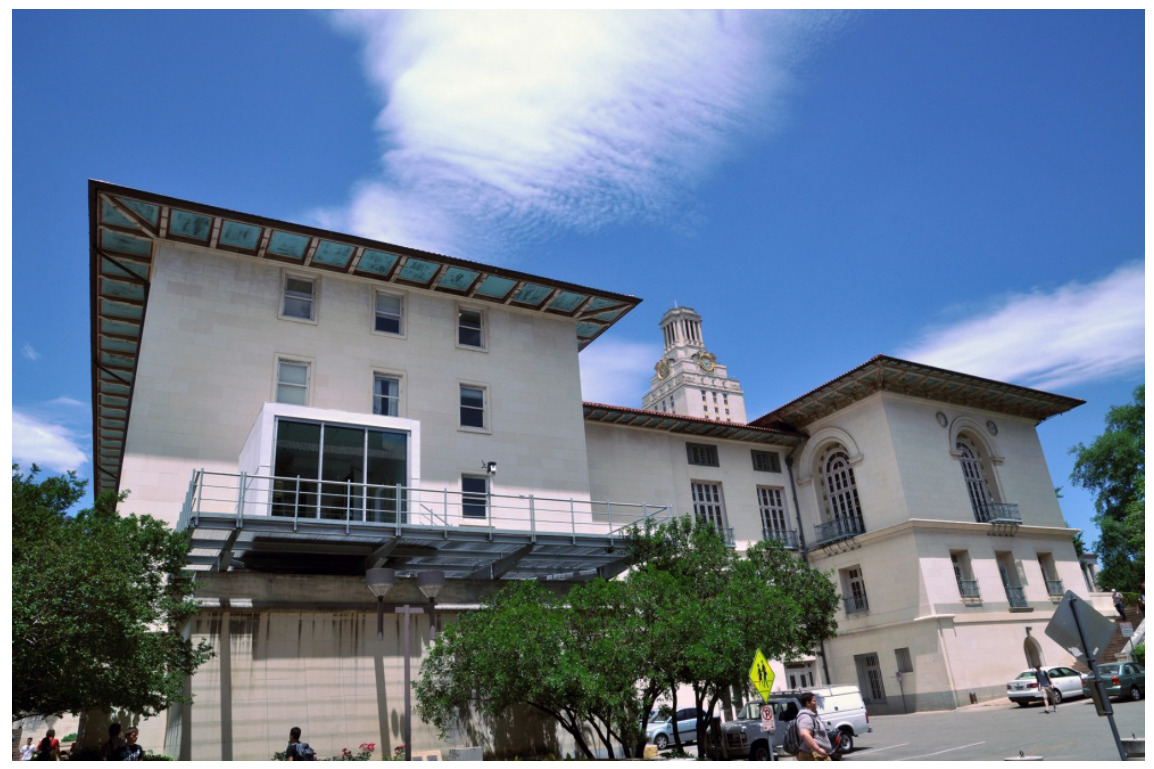

Figure 1: $\quad$ View of Facade Lab on platform.

The facility is able to measure the effects of innovative cladding materials and shading systems, which inform the field of experimental research as it relates to sustainable building in two significant ways. First, as an important subsystem 
within a building, the building envelope's primary task is to regulate the external climate conditions in order to provide comfortable internal conditions for the occupants. As a result, the envelope's performance has a significant impact on a building's overall energy consumption and dramatically influences the load on mechanical building services. Second, predicting a structure's thermal behavior is inherently dependent on the use of real-scale testing facilities, since the relationship between building volume and surface area is a crucial factor with regard to thermal gains and losses as well as energy demand, thus affecting internal comfort.

\section{General daylight testing parameters}

The Facade Lab allows for careful analysis of each interior plane (wall) of a space with a matrix of sensors which together provide remote readings of thermal and daylight data, as affected by any combination of shading device and climatic instance in time (see figure 2). For example, the ceiling plane, when properly illuminated by a light shelf or other reflective shading device, can carry light deep into a space, which is especially important in commercial buildings with deep floor plates.

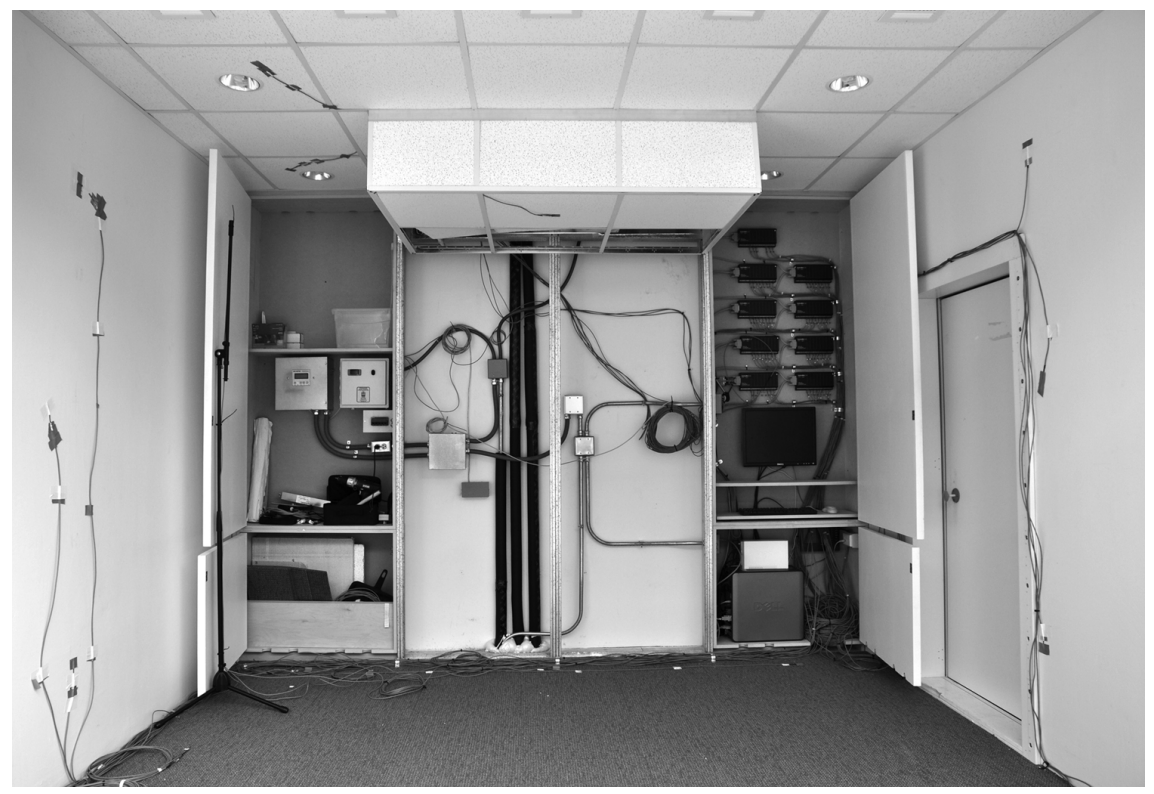

Figure 2: $\quad$ View of Facade Lab interior with remote sensor equipment.

The lab also allows for experiments with different materials which yield varying results in terms of thermal property capacities. Metal, wood, and plastic have very different properties in terms of thermal storage capacity as well as reflectance, as noted by Schittich [6], which can be measured quantifiably by the 
lab. For this particular research and prototypical design, daylight was the measured element of focus, as thermal impact calculations were not performed.

\section{Benchmark analysis to establish baseline parameters}

The Facade Lab allows for quantitative full-scale testing of conventional facade and shading systems, to establish baselines within the existing built environment.In order to be able to design optimised and innovative structures, it is critical to specifically understand conventional shading structures. Six generic benchmark shading structure types were tested for solar radiation in the specific hot, humid Austin climate in which the Facade Lab exists, via digital simulation processes, and the results were documented in the research of Bader [8].

\subsection{Horizontal louvers (Type 1)}

The type of horizontal louvers tested in this study consists of blinds which are perpendicular to the surface. They have a depth and a distance between each blind of $30 \mathrm{~cm}$. They span over the entire width of the window (see figure $3 \mathrm{a}$ ). The horizontal shading devices had a small improvement of $3.24 \%$ compared to southwest and $10.55 \%$ to the west. Horizontal louvers on the southwest allow $7.31 \%$ more solar radiation than for a west orientated surface. Horizontal louvers have a minimum shading coefficient (sc) of 0.47 (west) (see figure 4).

\subsection{Vertical louvers (Type 2)}

The design of the vertical blinds has a depth and a distance between each blind of $30 \mathrm{~cm}$ and covers the entire height of the window wall (see figure $3 \mathrm{~b}$ ). Vertical shading devices on west orientated surfaces provide $10.10 \%$ less shading than on the south and also $2.85 \%$ less than on the southwest. Compared to horizontal louvers, vertical blinds can only provide a minimum sc of 0.68 (west), no matter the orientation (see figure 4).

\subsection{Eggcrate shading structure (Type 3)}

Eggcrate shading structures are a combination of the horizontal and vertical blinds as described before. The square type is designed with an opening of 30 $\mathrm{cm}$ width/height and a depth of $30 \mathrm{~cm}$ (see figure $3 \mathrm{c}$ ). South orientated eggcrate shading structures deliver the best results with regard to shading. With $4.84 \%$ more shading in south than southwest and even $11.57 \%$ more shading than west, eggcrate shading structures show a minimum shading coefficient (sc) of 0.39 (west) in all orientations (see figure 4).

\subsection{Horizontally orientated honeycomb shading structures (Type 4)}

The honeycomb structure consists of symmetrical hexagonal components with a depth of $30 \mathrm{~cm}$. They have a diameter of $30 \mathrm{~cm}$ and a circumference of $9 \mathrm{~cm}$, resulting in $20 \mathrm{~cm}$ long edges. The maximum component height is $34 \mathrm{~cm}$. 
These honeycombs are wider than tall. They have two horizontal edges (see figure 3d). Similar to eggcrate structures, this type performs best in south. It provides $5.12 \%$ more shading than southwest and $10.70 \%$ more shading than west. With a minimum sc of 0.38 (west) this type of honeycomb has a similar behavior as an eggcrate type (see figure 4).

\subsection{Vertically orientated honeycomb shading structures (Type 5)}

This structure is similar to a horizontally orientated honeycomb but rotated by 90 degrees. Thus, the components are taller than wide and have two vertical edges (see figure 3e). This honeycomb, orientated towards south, performs best of all honeycomb structures in type and orientation. With an sc of 0.27 , it is slightly better but performs similar on south as the horizontally orientated type. It performs $4.50 \%$ (southwest) and $10.65 \%$ (west) better than in the other orientations. The minimum sc is 0.38 (west). Comparing the percentages of horizontally and vertically orientated honeycomb structures, it can be concluded that a change of its orientation has a slight impact on the shading performance. In general, vertically orientated honeycombs perform better than horizontally oriented types (see figure 4).

\subsection{Vertically orientated honeycomb with $1.4 \mathrm{~m}$ circumference (Type 6)}

The third variation of the honeycomb structure has a circumference equal to the sum of the sides of the square openings of the eggcrate structure, which is $1.4 \mathrm{~m}$. Thus, this honeycomb structure is actually bigger than type 4 or 5 (see figure $3 \mathrm{f}$ ). Similar, but with $3.69 \%$ (type 4 ) and $3.91 \%$ (type 5) less provided shading than other honeycomb types, this type also has its best performance on a south

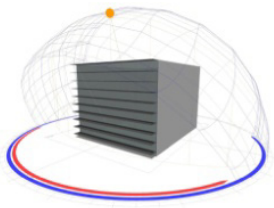

a)

Honizontal shading devices

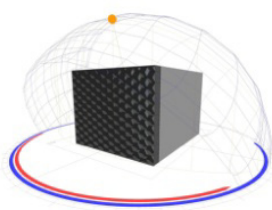

d) Honeycomb shading structure - horizontallty

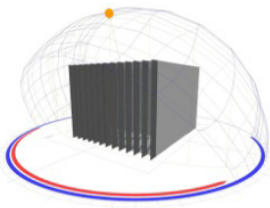

b)

Vertical shading devices

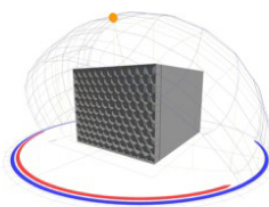

e)

Honeycomb shading structure - vertically

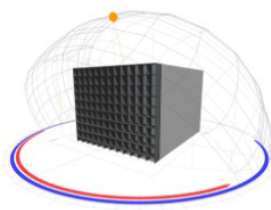

c)

Eggcrate shading structure - square

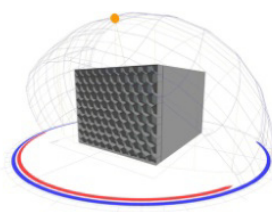

f) briented -4 circumterence

Figure 3: Generic conventional shading device benchmarks. 
orientated surface. As expected, it performs in every direction slightly worse than the other types. Compared to the south, this type provides $5.49 \%$ less shading in southwest and $11.64 \%$ in west (see figure 4 ).

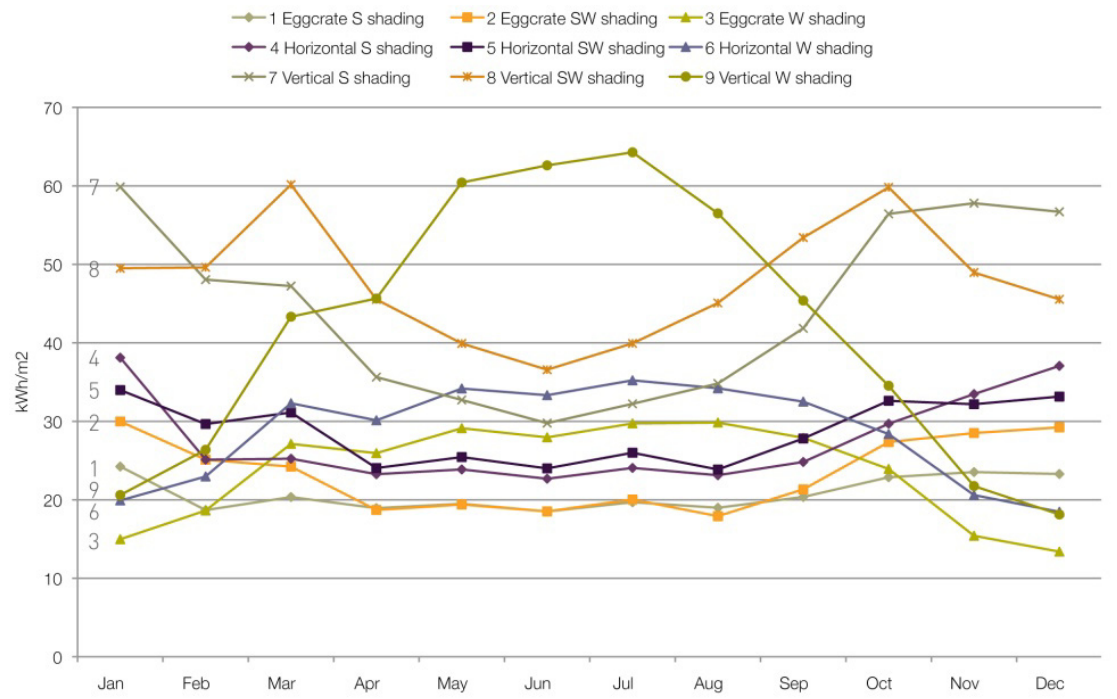

Figure 4: Monthly solar radiation comparison of benchmark shading devices.

\section{Prototype design methods and goals}

The shading device prototype design began with thorough research including a rigorous analysis of the times when sun shading is needed at the given geographic coordinates and south-facing orientation, and the surface needs of a shading device, based on an understanding of the local sun path, as spelled out by Bader [8]. In the hot, humid climate of Austin, Texas, the summer exterior temperature is above the comfort level more often than not, and thus direct summer solar radiation frequently leads to overheating. In contrast, direct winter sunlight is desired in order to reduce heating loads and electrical consumption by artificial lighting. Therefore, the first shading prototype was designed to provide full shading in the summer and direct solar exposure in the winter, while existing as a static structure, as well as optimising views out from the inside.

After carefully considering the advantages and disadvantages of each generic benchmark shading device type, a honeycomb variant was chosen as the general shape of the unit or module of the experimental prototypical shading device (see figure 5). This decision took into consideration solar performance as well as construction material assembly. First, the honeycomb form loosely mimics the semicircular daily path of the sun. Secondly, the hexagon shape is structurally more rigid than a rectangular form, due to its diagonal members which utilize the structural principle of triangulation. The pattern also uses a minimal amount of 
surface area to create a lattice of cells within a given volume and the hexagonal forms stack well to reduce material. Lastly, the novelty of the form was a driver in the pursuit to explore undocumented territory in shading device design, as noted by Bader [8].
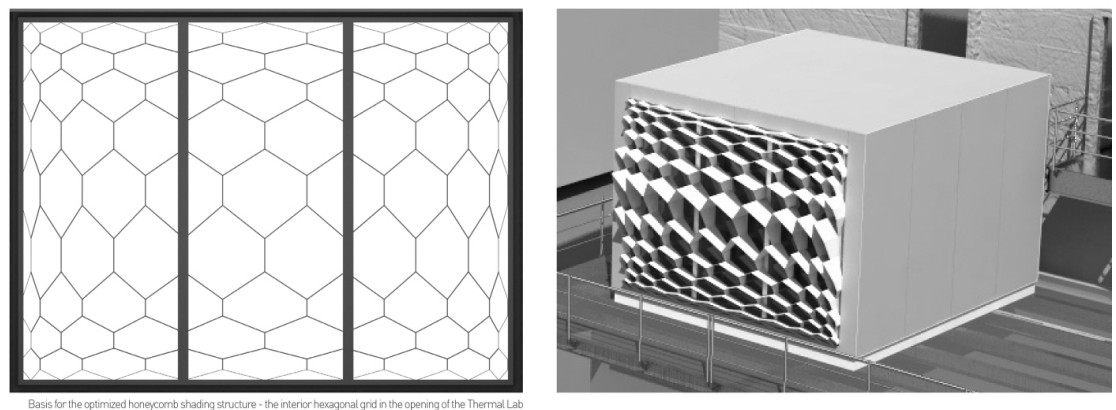

Figure 5: Virtual development of Experimental Prototype Structure.

\section{Prototype fabrication and comparative performance results}

The experimental prototype was cut out of polypropylene sheets with a CNC (Computer Numerical Control) Router and assembled in units (see Figure 6).Results showed that the optimised honeycomb experimental prototype structure provides the lowest sc for south relative to conventional counterparts, but performs best for southwest and west. For south, the sc is provided by the vertically oriented honeycomb structure. With an sc of 0.27 the structure provides almost $43 \%$ more shading than the optimised honeycomb structure. On southwest, the optimised honeycomb structure provides $15 \%$ more shading than the vertically orientated honeycomb structure, which provides the second best sc. Similar results for west, where the optimised honeycomb shading structure provides an sc of 0.29 which is $21.2 \%$ better than the second best shading structure, again the vertically orientated honeycomb shading structure. But again, the results could also show that the optimized structure only provides more diffuse solar radiation than the others and thus, it simply allows a higher degree of visual comfort with full shading from March until September, the critical months with regard to high temperatures.

Due to the minimised use of material, the experimental optimised honeycomb prototype shading structure is highly competitive to the other benchmark shading devices (see figure 7). Ultimately, it performs third on area of unrolled shading structure and performs best on total volume of shading structure. Even though it has a slightly larger area of visible shading structure than the honeycomb shading structure with a circumference of $1.4 \mathrm{~m}$, it provides a high degree of visual contact due to the enlarged openings in defined regions, which provide the same sc as smaller components. Furthermore, the optimised honeycomb form of the experimental prototype offers a unique alternative to conventional vertical and horizontal louvers, and is far more interesting and aesthetically intriguing than conventional louver types (see Figures 8 and 9). 


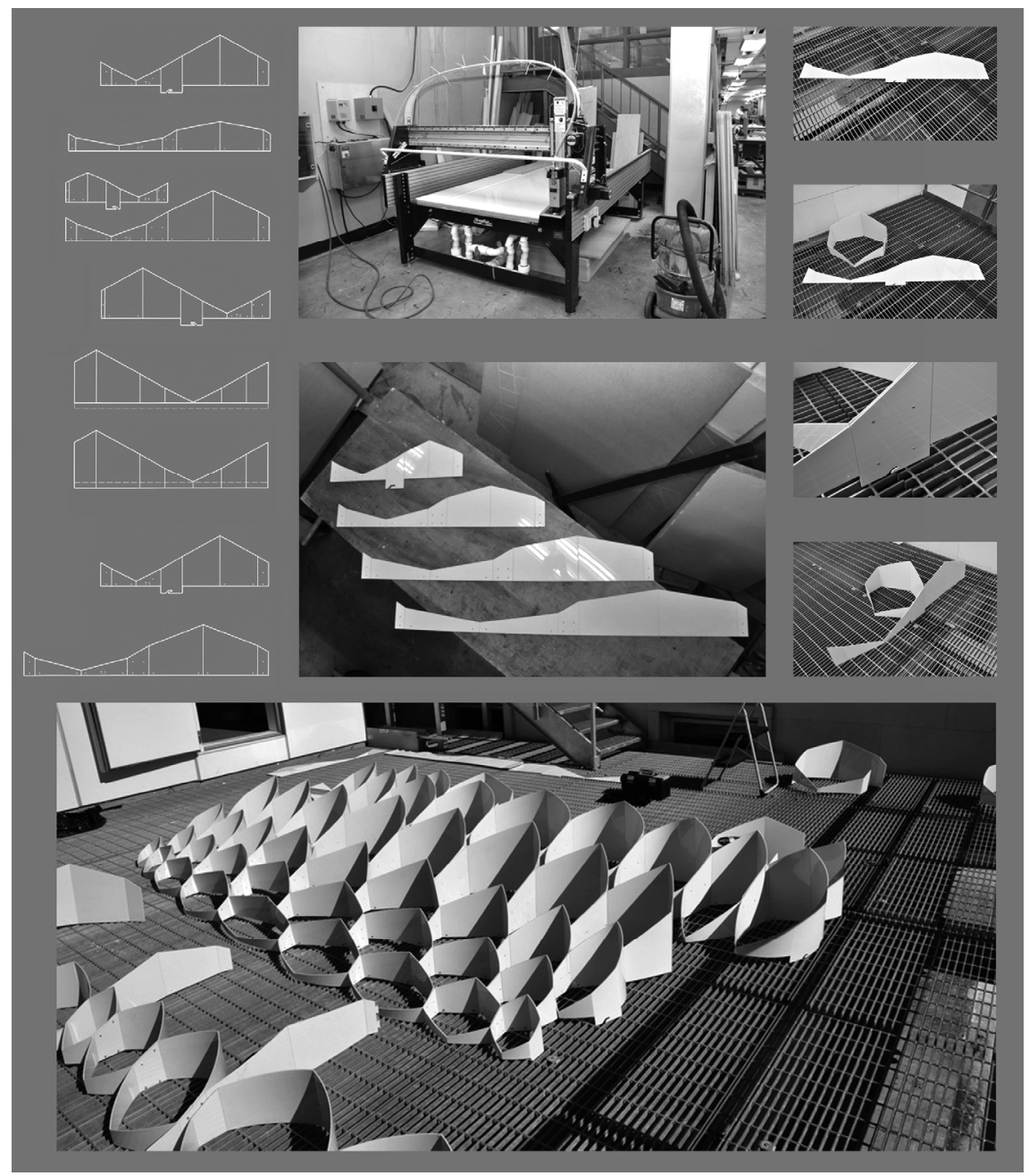

Figure 6: Construction and assembly of experimental prototype structure.

\section{Conclusion}

Amidst increasing pressure to improve building sustainability, there exists a dire need for collaboration between architects and engineers to optimize quantitative and qualitative building performance, including merging between the two disciplines. By increasing our quantitative understanding of the cause and effect relationship between shading device design and daylight transmission, qualitative design processes can be rigorously measured in an integrated manner, 
68 Lighting in Engineering, Architecture and the Environment
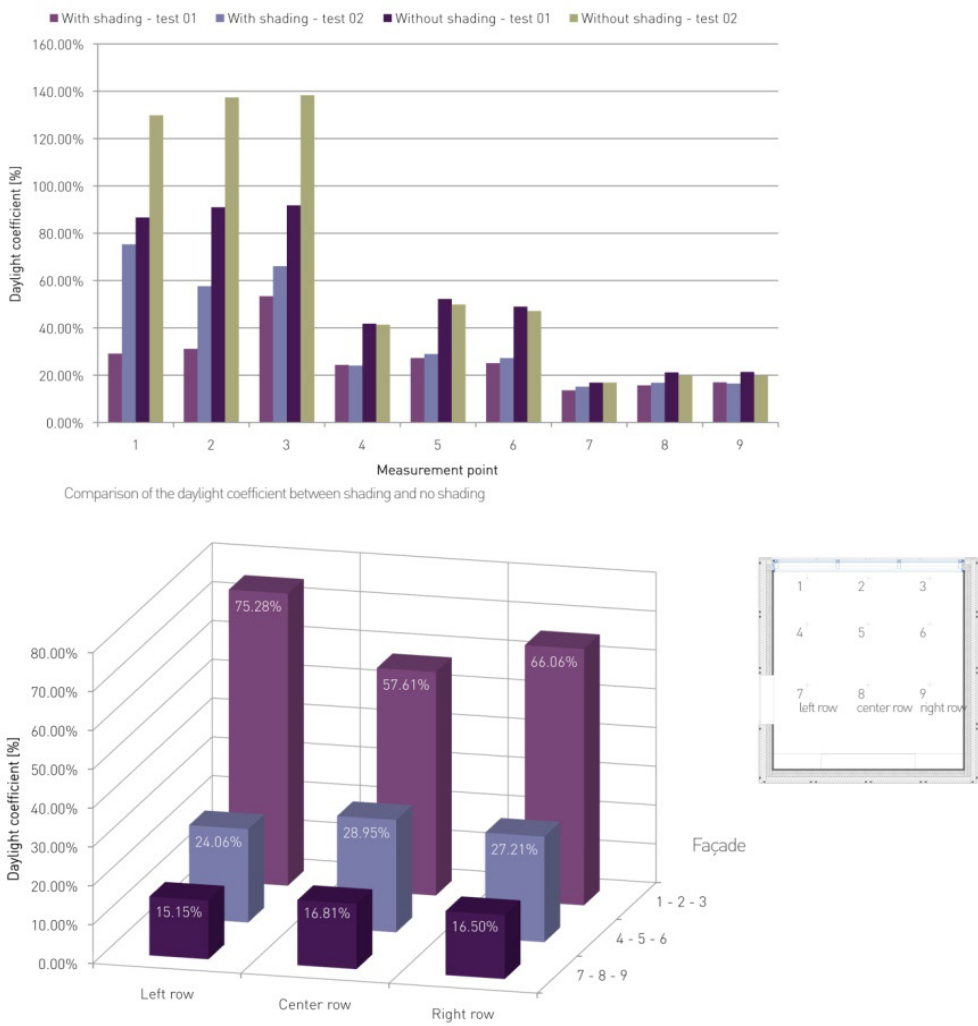

Distribution of daylight coefficients in the Thermal Lab with shading - test 02

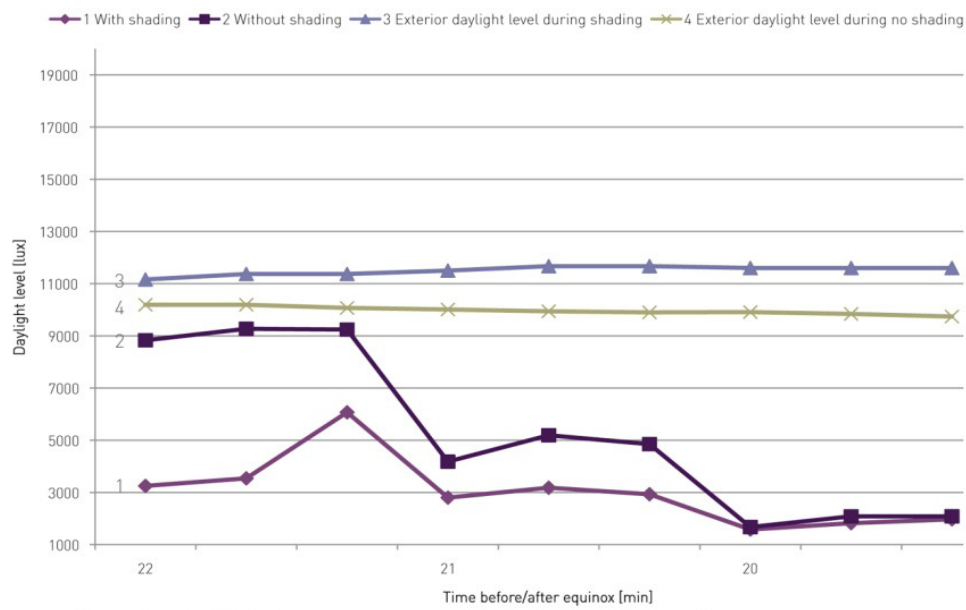

Comparison of daylight level measurements between shading and no shading - test 01

Figure 7: Effect of experimental prototype structure on daylight distribution. 


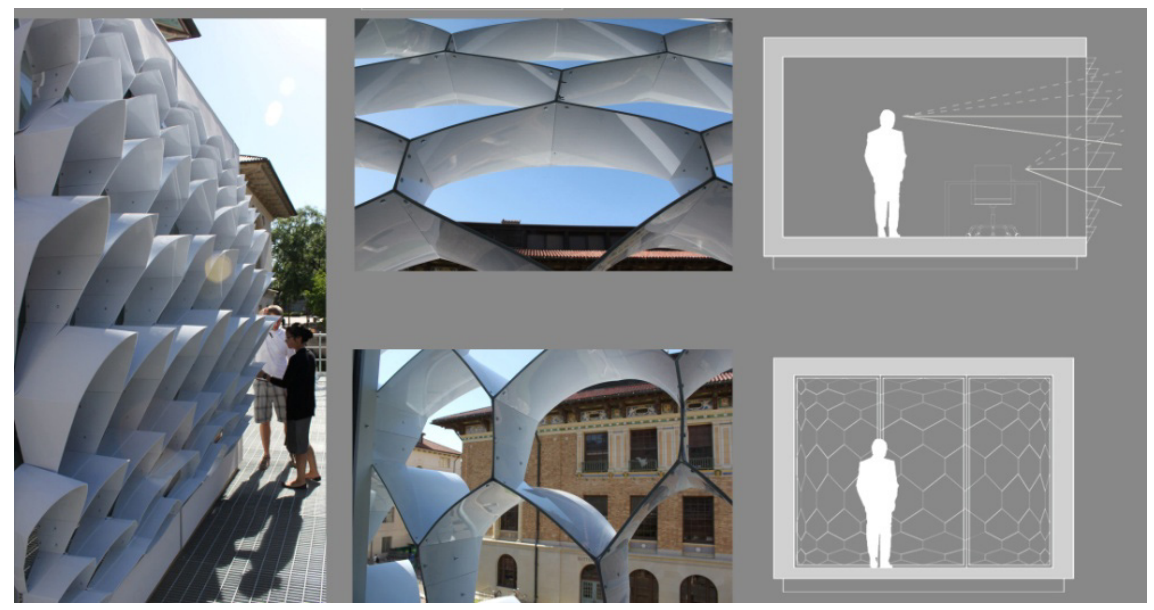

Figure 8: $\quad$ View of experimental prototype shading structure on Facade Lab.

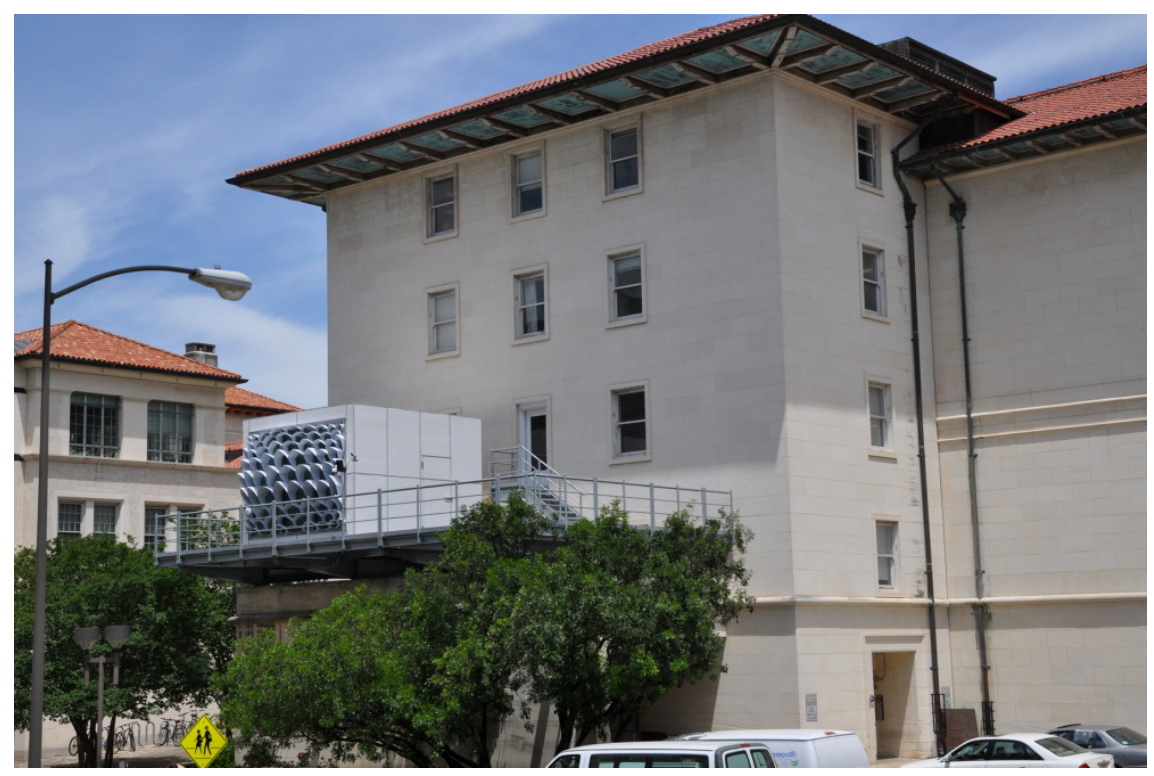

Figure 9: $\quad$ View of experimental prototype shading structure on Facade Lab.

thus creating some overlap between the roles of the architect and engineer. This research suggests there can exist a new middle working ground toward the quantifiable and qualitative design alternative shading solutions with improved functional, ecological and aesthetic properties which can be adapted and applied in future developments in various climatic conditions. 
70 Lighting in Engineering, Architecture and the Environment

\section{References}

[1] Minnaert M. (1954). The Nature of Light and Colour in the Open Air. USA: Dover Publications Inc.

[2] Augustin S. (2009). Place Advantage: Applied Psychology for Interior Architecture. New Jersey: John Wiley \& Sons, Inc.

[3] U.S. Green Building Council, Green Building Facts, http://www.usgbc.org /ShowFile.aspx?DocumentID=5961.

[4] Koster H. (2004). Dynamic Daylighting Architecture: Basics, systems, Projects. Basel: Birkhauser.

[5] Herzog, Thomas. (2004) Facade Construction Manual. Basel: Birkhäuser.

[6] Schittich, Christian. (2001). Building Skins: Concepts, Layers, Materials. Basel: Birkhäuser.

[7] Leslie, R.P. (2003). Capturing the daylight dividends in buildings: why and how? Building and Environment, 38, 381-385.

[8] Bader S. (2010). High-performance facades for commercial buildings. M.S.S.D. Thesis, UTSOA Center for Sustainable Development (USA). 